\title{
Human papillomavirus in squamous cell carcinoma of the oesophagus associated with tylosis
}

\author{
M T Ashworth, I W McDicken, S A Southern, J R G Nash
}

\begin{abstract}
Human papillomavirus (HPV) may have a pathogenic role in squamous cell carcinoma of the oesophagus. Tylosis, an inherited thickening of the skin of the palms and soles, was associated with a high risk of developing squamous cell carcinoma of the oesophagus among members of a large family in Liverpool. The resected carcinomas of the oesophagus was examined from four such patients with DNA probes to HPV types $6,11,16,18,31,33$ and 35 using in situ hybridisation under conditions of high stringency. No reaction was detected. The oesophageal biopsy specimens from 10 tylotic subjects without carcinoma were also examined. No HPV DNA was detected.

It is concluded that there is no evidence that HPV infection has a role in the development of squamous cell carcinoma of the oesophagus in tylosis.
\end{abstract}

(F Clin Pathol 1993;46:573-575)

Palmoplantar keratoderma (tylosis) is an autosomal dominant inherited disorder, characterised by thickening of the skin of the soles and the palms. In two large Liverpool families it is associated with a high risk of developing squamous cell carcinoma of the oesophagus, first described in $1958 .^{1}$

The resected specimen of a carcinoma of the oesophagus from a patient with tylosis showed cells which were indistinguishable from koilocytes, both at the light microscopic and ultrastructural level, and it was this finding which prompted us to look more closely at the oesophageal mucosa in tylosis to see whether HPV infection was associated with the development of squamous cell carcinoma in these subjects.

\section{Methods}

Paraffin wax blocks were obtained from four patients with tylosis who had had the oesoph-

Patient details

\begin{tabular}{llllll}
\hline Case No & Age & Sex & Pedigree $^{\star}$ & Lesion & Year of resection \\
\hline 1 & 52 & M & SIII 56 & Carcinoma & 1963 \\
2 & 51 & F & SIV 17 & Carcinoma & in situ \\
3 & 62 & F & SIII 54 & Carcinoma & 1986 \\
4 & 50 & F & SIV 57 & Carcinoma & 1991 \\
\hline
\end{tabular}

^Pedigree number assigned in: Harper PS, Harper RMJ, Howel-Evans AW. Carcinoma of the Oesophagus with tylosis. Qf Med 1970;39:317-33. agus removed for carcinoma of the oesophagus (table).

All the blocks contained areas of carcinoma, either in situ or invasive. Paraffin wax embedded oesophageal biopsy specimens from 10 subjects from the same family with tylosis were examined. These specimens showed varying degrees of inflammation and other minor changes, but no evidence of neoplasia.

Sections were cut at 3-5 $\mu \mathrm{m}$ and attached to glass slides which were then placed in two changes of xylene, each for 5 minutes. The sections were rehydrated through graded alcohols to Analar water (BDH Laboratory Supplies, Poole Dorset, England), treated with $0 \cdot 2 \mathrm{~N}$ hydrochloric acid for 20 minutes, and then washed briefly in Analar water. After this the sections were incubated at $70^{\circ} \mathrm{C}$ for 30 minutes with double strength SSC $(0 \cdot 015 \mathrm{M}$ citric acid, $0 \cdot 15 \mathrm{M}$ sodium chloride) and then washed briefly in Analar water. They were then incubated with $0.05 \mathrm{mg} / \mathrm{ml}$ proteinase $\mathrm{K}$ in $20 \mathrm{mmol}$ TRIS-HCL at $\mathrm{pH}$ $7 \cdot 4$, containing $2 \mathrm{mM}$ calcium chloride for 15 minutes at $42^{\circ} \mathrm{C}$. There followed two washes in Analar water, each for 5 minutes. The sections were then dehydrated in graded alcohols and allowed to dry. To the dried sections were applied $10 \mu \mathrm{l}$ of biotinylated HPV DNA probe. The sections were placed in a modular incubator chamber, through which boiling water was passed to maintain an ambient temperature of $93^{\circ} \mathrm{C}$, for 5 minutes. The sections were cooled rapidly on ice and hybridised at $42^{\circ} \mathrm{C}$ overnight. The coverslips were removed and two successive washes (double strength SSC for 30 minutes at room temperature and $0 \cdot 1 \mathrm{SSC}$ for 30 minutes at $42^{\circ} \mathrm{C}$ ) were performed, followed by a wash at $42^{\circ} \mathrm{C}$ for 15 minutes with $0 \cdot 1$ SSC. They were rinsed in TBS $(0.05 \mathrm{M}$ TRIS-HCL, $0 \cdot 15 \mathrm{M} \mathrm{NaCl}$ ). Streptavidin (Dako) 1 in 100 in TRIS buffered saline (TBS) was applied for 30 minutes and the sections then washed in TBS for 10 minutes. Biotinylated alkaline phosphatase 1 in 100 was applied for $30 \mathrm{~min}$ utes, followed by a wash in TBS for $10 \mathrm{~min}$ utes. Streptavidin and biotinylated alkaline phosphatase were applied again for the same lengths of time. The sections were then developed microscopically with Fast Red substrate for about 2 hours; a light haematoxylin counterstain was applied and the sections mounted in aqueous medium. HPV DNA probes to HPV types 6,$11 ; 16,18 ; 31,33,35$ were supplied ready to use from Life Technologies. 
HeLa cell nuclei showing positive staining for $H P V$ 18

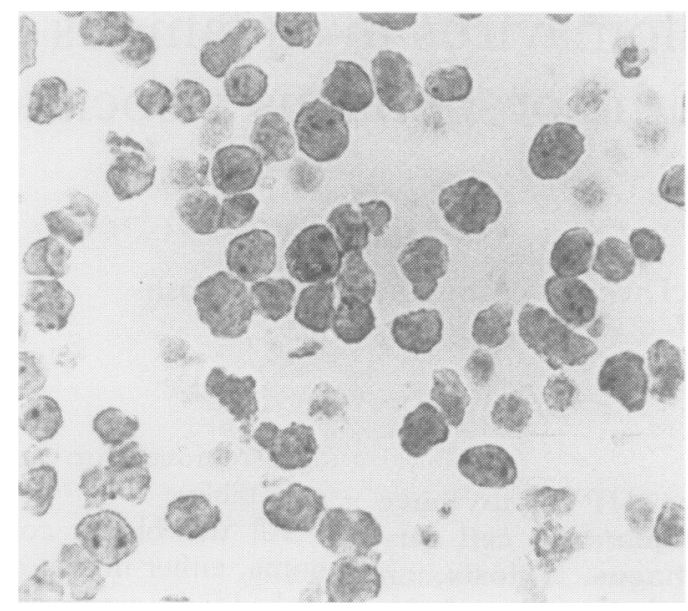

A positive DNA control (total human genomic DNA; Life Technologies) was included to verify fixation, digestion, and denaturation conditions of every tissue tested. A negative DNA control was used, specific for the plasmid vector $\mathrm{pBR} 322$.

HPV controls used were a known positive cervical wart containing episomal HPV 6,11, HeLa cells containing integrated HPV 18, and a known positive cervical cancer containing episomal HPV $31,33,35$. The control cervical tissue and the HeLa cells were processed in a similar manner to the oesophageal tissue; all were fixed in buffered formalin, dehydrated through graded alcohols, cleared in xylene and embedded in paraffin wax.

\section{Results}

Positive labelling of the control tissues for all probes occurred. The HeLa cells, which contain 30-40 copies of HPV 18 DNA, showed positive staining for HPV 18, thus showing the sensitivity of the in situ method used (figure).

No labelling was seen in the tissues from the tylotic cases. Neither the carcinomas nor the non-carcinomatous tissue showed any evidence of HPV DNA under conditions of high stringency. Under conditions of low stringency there was no reaction product demonstrable.

\section{Discussion}

Human papillomavirus infection has been implicated in squamous cell carcinoma of the uterine cervix. A considerable body of evidence now indicates that it is an important, if not major, factor in the development of that tumour as well as other tumours of the anogenital region. ${ }^{2}$

Several authors have studied the association between human papillomavirus infection and squamous cell carcinoma of the oesophagus. Syrjänen, the first to do so, examined resection specimens from 60 patients with invasive squamous cell carcinoma of the oesophagus and found that $40 \%$ had mor- phological features of HPV infection. ${ }^{3}$ Winkler et al examined 73 cases of epithelial hyperplasia and two papillomas from the oesophagus and found morphological evidence of HPV infection in $13(17 \cdot 3 \%)$ cases. Using immunoperoxidase staining, four of the cases were positive for HPV antigen. ${ }^{4}$

In 1986 Hille et al reported on their investigation of HPV infection in association with carcinoma of the oesophagus in black South Africans. ${ }^{5}$ They examined oesophageal biopsy specimens from 70 black men with a diagnosis of oesophageal squamous cell carcinoma and also examined oesophageal resection specimens from 10 of these cases. They found what they considered to be morphological evidence of HPV infection in 23 (33\%) cases and demonstrated positive immunostaining for HPV antigens in seven of these latter cases using commercially available rabbit antiserum to genus specific structural antigens of the papillomavirus group (DakoB580).

Kulski et al examined archival material from 120 cases of oesophageal squamous cell carcinoma in Western Australians using morphological, immunohistochemical, and DNA hybridisation techniques. ${ }^{6}$ They found changes consistent with koilocytosis in $25 \%$ of cases, but they noted that in none of the cases was there change identifiable as a definite HPV effect. No cases were positive using HPV genus specific capsid antigen immunostaining. By using filter in situ hybridisation methods with probes for HPV types 11, 13, 16 and 18 , however, they demonstrated positivity in five of the 10 cases so studied.

Using the polymerase chain reaction to amplify HPV related DNA sequences, Kiyabu et al were unable to demonstrate HPV 16 or 18 sequences in 13 oesophageal carcinomas that they studied in Los Angeles, USA. ${ }^{7}$ They did not use probes to HPV types 11 or 13. Loke et al examined 37 cases of oesophageal squamous cell carcinoma in Hong Kong by DNA slot-blot analysis and in situ hybridisation using type specific probes for HPV $6,11,16$ and 18. In no case could they demonstrate any viral DNA. ${ }^{8}$ In 1990 Chang et al published their results of a study of 51 oesophagectomy specimens from Linxian county in Henan Province-a high risk area for carcinoma of the oesophagus. ${ }^{9}$ They were able to show morphological evidence of HPV infection in $25(49 \%)$ cases and showed HPV DNA by in situ hybridisation with probes to HPV types $6,11,16$ and 18 in 22 cases. The HPV DNA was predominantly in the squamous epithelium surrounding the carcinomas rather than in the carcinoma cells themselves. HPV 16 and 18 were the commonest types.

In at least one of our carcinoma cases there is morphological evidence consistent with HPV infection. We have been unable to show the presence of HPV DNA in any of our cases. The possibility remains that HPV types other than those tested for may have caused the changes that we have seen. The copy 
number of HPV may have been very low and would perhaps require the polymerase chain reaction to demonstrate low copy numbers of the virus. Morris and Price have speculated, on the basis of their observations, that carcinoma of the oesophagus may be caused by a defect in the Langerhans' cell population in the oesophagus following infection with HPV. ${ }^{10}$ We have found no evidence of reduced Langerhans' cell numbers in the oesophagus of subjects with tylosis (unpublished observations).

We have found that in the tylotic oesophagus that the major histocompatability complex class II molecule HLA-DR is expressed on epithelial cells in those cases that have gone on to develop carcinoma (unpublished observations). Viruses such as herpes simplex virus are known to induce expression of HLA-DR on oesophageal squamous epithelial cells, but HPV has not been proved to do so.

In tylosis there is a genetic predisposition to the development of squamous cell carcinoma of the oesophagus which may interact with an environmental agent to cause overt malignancy. We have found no evidence in this limited study that the environmental agent is human papillomavirus.

1 Howel-Evans W, McConnell RB, Clarke CA, Sheppard PM. Carcinoma of the oesophagus with keratosis palmaris et plantaris (tylosis). $Q \mathcal{F}$ Med 1958;27:413-29.

2 zur Hausen $H$. Papillomaviruses in anogenital cancer as a model to understand the role of viruses in human cancers. Cancer Res 1989;49:4677-81.

3 Syrjänen KJ. Histological changes identical to those of condylomatous lesions found in esophageal squamous coll carcinomas. Arch Geschwulstforsch 1982;52:283-92.

4 Winkler B, Capo V, Reumann W, et al. Human papilloWinkler B, Capo V, Reumann W, et al. Human papillo-
mavirus infection of the esophagus. A clinicopathologic mavirus infection of the esophagus. A clinicopathologic
study with demonstration of papillomavirus antigen by study with demonstration of papillomavirus antigen by
the immunoperoxidase technique. Cancer 1985;55: 149-55.

5 Hille JJ, Margoulis KA, Markowitz S, Isaacson C. Human papillomavirus infection related to oesophageal carcinoma in black South Africans. S Afr Med $f 1986$; 69:417-20.

6 Kulski J, Demeter T, Sterrett GF, Shilkin JB. Human papillomavirus DNA in oesophageal carcinoma. Lancet 1986;ii:683-4.

7 Kiyabu MT, Shibata D, Arnheim N, Martin JW, Fitzgibbons PL. Detection of human papillomavirus in formalin-fixed, invasive squamous carcinoma using the polymerase chain reaction. Am $\mathcal{F}$ Surg Pathol 1989;13: 221-4.

8 Loke SL, Ma L, Wong M, Srivastava G, Lo I, Bird CC. Human papillomavirus in oesophageal squamous cell carcinoma. $₹$ Clin Pathol 1990;43:909-12.

9 Human papillomavirus (HPV) DNA in esophageal precancer Lesions and squamous cell carcinomas from China. Chang F, Syrjänen S, Shen Q Ji H, Syrjänen $\mathrm{K}$. Int $\mathcal{F}$ Cancer 1990;45:21-5.

10 Morris H, Price S. Langerhans' cells, papillomaviruses and oesophageal carcinoma. A hypothesis. S Afr Med $\mathcal{F}$ 1986;69:413-17. 